\title{
Cross-Cultural Training: The Importance of Volunteering Abroad in Medical School
}

Nidhi Ravishankar.'

\section{The Experience}

About the Author: Nidhi Ravishankar is entering second year medical school at the Windsor University school of Medicine.
Submission: Jul 15, 2014 Acceptance: Jul 26, 2014
Volunteering overseas whilst in medical school has proved extremely beneficial not only for my academic growth, but also for professional and personal growth.

There is a marked disparity between what is taught in medical schools and what is expected of physicians in practical aspects.' In most medical schools, medical students acquire their training and skills in large tertiary care hospitals, where the focus is placed on making the right diagnosis. This takes precedence over the interpersonal communication between the health-care practitioner and the patient. I was able to learn such skills through direct contact with the patients, as well as medical skills such as taking blood pressure, blood glucose levels, patient history, neurological examination and basic physical examination.

During my time in St. Kitts, I volunteered with a group called "Students For Health (SFH)" - a student-run volunteering clinic offering free health-checks to the local community. This community initiative was bolstered by Dr. Vishal Surendar of Windsor University School of Medicine who oversees the entire group.

As a volunteer for SFH, I was able to comprehend the huge difference between the standards of medical practice in the developed and developing worlds. As told by the locals who attended the clinic, the major hospital on the island, Joseph N. Frances General Hospital, dealt mainly with immediate and minor cases and patients were seen in order of severity. As a result, frequent health checkups were left to be conducted in community clinics which were often said to be "crowded". SFH therefore proved to be a helpful alternative for the community to acquire health-checkups without having a long wait.

During my first semester of medical school, there was very little time to learn clinical skills effectively such as taking blood pressure, using a stethoscope, taking blood glucose etc. because of the rapid pace of the subjects. SFH allowed me to build these skills through rigorous training and an examination, and implement them on patients. The training allowed me to gain
Figure 1. Consulting on the Treatment Regimen for a Patient's Hypertension.

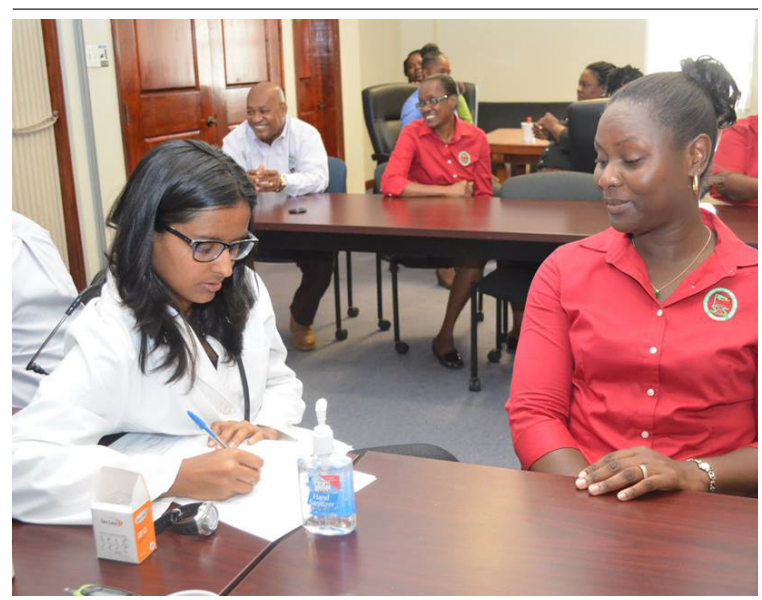

confidence in my clinical knowledge so that my clinical years can be more productive and enjoyable.

When I went onto the field and became part of a team who offered the heath checkups every week, I came in contact with patients who had illnesses and conditions that I rarely saw in the developed world. Patients came in with Marfan syndrome, Paget's disease and other conditions that I had only learned in class. It was an extremely meaningful experience to observe and interact with patients with these conditions. I was able to learn about them through a more personal approach, rather than just an academic one.

In addition, SFH also offered me the opportunity to model professionalism as well as ethical and culturally sensitive treatment of patients. As a student from Toronto, Ontario, one of the biggest and most multicultural cities in Canada, I was experienced in communicating with patients from various backgrounds, but my time in St. Kitts proved that I had a lot more to learn. Although advanced technology or a more pleasant environment may be conducive to better-quality care, the evidence indicates only a weak link between such structural elements and better health outcomes. ${ }^{2}$ This was especially evident when we had

${ }^{1}$ Medical student, University of Windsor, Canada. 
many tourists visiting our clinic indicating that they had rarely seen freeclinics being offered in their respective countries. Most of these foreign patients were well-versed in medicine, however it was surprising to see that one of them was unaware of his hypercholesterolemia. Although there are many benefits to being served medically in developed countries like Canada and the United States, the patient doctor relationship is very minimal due to the high volume of patients. They were very receptive to the clinic because they appreciated the personal depth that came with the visit.

As a health-care provider, we are expected to approach cross-cultural education that can be used to care for any patient, anytime, anywhere. Although a purely algorithmic approach is being taught in medical schools, the best kind of learning comes from interacting with various patients where we can at least have a framework to care for patients regardless of race, ethnicity or cultural background.

\section{References}

1. Macfarlane S, Racelis M, Muli-Musiime F. Public health in developing countries. Lancet. 2000 Sep 2;356(9232):841-6.

2. Donabedian, A.The Definition of Quality and Approaches to Its Assessment. Ann Arbor, MI: Health Administration Press; 1980

\section{Acknowledgments}

I would like to acknowledge the Students for Health team at Windsor University School of Medicine at St. Kitts.

Conflict of Interest Statement a Funding

The author has no funding, financial relationships or conflicts of interest to disclose.

Author Contributions

Write the manuscript: NR

Cite as:

Ravishankar N. Cross Cultural Education: The Importance of Volunteering Abroad in Medical School. Int J Med Students. 2014 Jul$0 \mathrm{ct} ; 2(3): 140-1$ 